\title{
Reflections on a new community partnership: How does an engineering sum- mer camp evolve to meet the needs of an increasingly diverse student popula- tion? (WIP)
}

\section{Emily E. Liptow, California Polytechnic State University, San Luis Obispo}

Emily Liptow currently works at a tech startup accelerator in Cleveland $\mathrm{OH}$ where she manages a coworking space and promotes community and diversity in the city's entrepreneurship ecosystem. She served as an AmeriCorps VISTA member at California Polytechnic State University in San Luis Obispo where she was involved with a variety of diversity and inclusion efforts in the College of Engineering ranging from student support programs, faculty bias awareness trainings, and inclusive cultural change. Prior to her work at Cal Poly, received a B.S. in Industrial and Systems Engineering from Ohio State University, where she was also very involved with social justice initiatives.

\section{Dr. Katherine Chen, Worcester Polytechnic Institute}

Dr. Katherine C. Chen is the Executive Director of the STEM Education Center at Worcester Polytechnic Institute (WPI). Her degrees in Materials Science and Engineering are from Michigan State University and MIT. Her research interests include pre-college engineering education and equity in education.

Berizohar Padilla Cerezo

Maria Manzano, California Polytechnic State University, San Luis Obispo 


\section{Reflections on a new community partnership: How does an engineering summer camp evolve to meet the needs of an increasingly diverse student population? (WIP)}

\section{Introduction}

EPIC (Engineering Possibilities in College) is a week-long summer camp designed to encourage middle and high school students to consider pursuing engineering in college. Since it first began in 2007 with 20 female high school students, it has grown to serve over 600 middle and high school students with four one-week sessions. Recently, EPIC partnered with the Migrant Education Program (MEP), a federal program that provides academic support to children of migrant workers in agriculture, diary, or fishing industries. For the past two summers, MEP students have made up 50\% (about 80 students) of the middle school week. Though EPIC has always focused on attracting and engaging a diverse set of students, EPIC was not originally designed to meet the specific needs of MEP students. MEP students typically experience frequent relocation as their parents find work which can cause disruptions in their academics and social lives. For most MEP students, English is their second language, and a large number of the students do not speak Spanish but rather a dialect of Mixteca. Thus, even in their "native countries" they were already at a disadvantage for not speaking Spanish, and most of their parents did not attend grade school. These students were enrolled in EPIC through their MEP chapter, so many students may have felt that they were placed in the camp versus selecting it for themselves, and for most students, it was their first experience at an overnight camp. In our attempt to ensure a positive EPIC experience for all students, we provided an inclusivity training for camp counselors and lab instructors. We also translated some camp materials in Spanish, and some of the EPIC counselors and staff members were bilingual.

With this work-in-progress paper, we share our reflections and lessons learned, and we welcome feedback from the engineering education community. We present the steps taken in preparation for the MEP students, and examine how effective those steps were. Preliminary data from the post survey are presented to help us highlight what went well during EPIC and areas for improvement.

We consider a few important questions: How does an engineering summer camp evolve to meet the needs of an increasingly diverse student population? How can the observations and experiences of the EPIC staff, counselors, and instructors help improve the camp? What are the essential steps needed to achieve our goals of being inclusive? What are the lessons learned that could help others with similar programs adapt to broaden their participation?

\section{EPIC Background and Structure}

EPIC began in 2007 as a week-long, half-day camp that served 20 female high school and middle school students. Since then it has grown to serve over 600 students from grades 6 th through 12th with four one-week sessions of 160 participants each (Figure 1). EPIC was developed with the goal of exposing middle and high school students to engineering, so that they might consider pursuing engineering in college $(1,2)$. As a residential camp, EPIC provides students with the opportunity to experience campus life so that they can begin envisioning themselves as college students. Counselors are current college engineering students that are role models for the camp participants. 


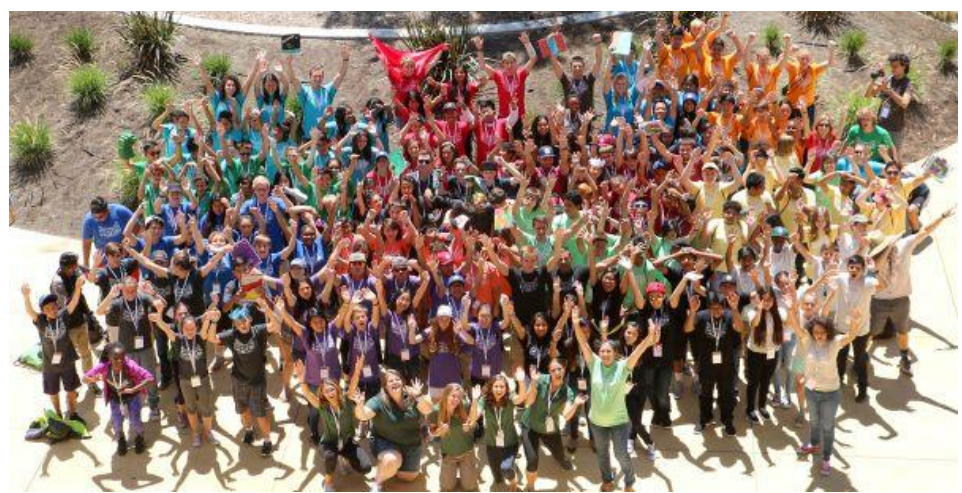

Figure 1: EPIC students at final day of camp.

During EPIC, students participate in eight 2-hour engineering labs over the course of the week. The labs are primarily taught by university faculty and cover a range of engineering topics and activities such as nanotechnology, scribbler robots, welding, phone apps, building bridges and much more. Each day, students participate in interactive presentations that expose them to important college topics such as financial aid and life on campus, and they get to hear from an industry speaker who shares about their engineering journey and the engineering company they work for. Throughout the week students also participate in typical social camp activities, including rock climbing, a pool party, and a talent show. An example of the EPIC weekly schedule can be seen in Appendix I.

\section{EPIC \& MEP Collaboration}

For the past two summers, students from the Migrant Education Program (MEP) participated in EPIC. MEP is a federal program that provides academic support to children of migrant workers in agriculture, diary, or fishing industries. MEP funds educational programs to support students during transitions between schools and ensure their success.

MEP students have a unique set of strengths and challenges that sets them apart from most of the students who typically attend EPIC. MEP students must overcome many barriers as they go through the education system. These students typically experience frequent relocation, sometimes across state borders, as their parents find work. Because of this, students may face disruptions in their education as they switch school districts, and many do not have the opportunity to create long term friendships or mentorship. Most MEP students are bilingual with English as their second language. Many students' parents speak Mixteco which is a dialect from Mexico that can have over 30 variations of it, depending on what area of Mexico the family is from. The students then need to learn Spanish to converse with friends and the general community, and English to converse with teachers. Many migrant worker families are at or below the poverty level which is a huge burden for parents and children, often meaning there's a lack of basic resources and opportunities. Even in their native country, parents didn't have access to education because of cost and language barriers. So for many MEP families, they see university education as a near impossible opportunity for their children.

In EPIC's efforts to reach underserved communities and broaden the participation in engineering, we developed a relationship with a local MEP branch. During the summers of 2016 and 2017, MEP students have made up 50\% of EPIC's middle school week. Though EPIC has 
always focused on attracting and engaging a diverse set of students, EPIC was not originally designed to meet the specific needs of MEP students.

EPIC's steps to prepare for MEP students

In our best effort to ensure a positive EPIC experience for all students, we took a holistic approach to improve the inclusivity of the camp. Our efforts were focused on preparing EPIC staff to support the MEP students; however, most of the changes we implemented would benefit all EPIC students. Below is a summary of the steps we took leading up to the camp:

1. Close collaboration with MEP Directors

The EPIC Director worked very closely with the co-directors of MEP. An initial meeting with the MEP directors of the different regions is conducted yearly to discuss their goals and how EPIC can assist in meeting them. This meeting also establishes the following: MEP budgeted amount for EPIC participants, amount of EPIC scholarships, number of participants, contacts for each regions, benchmark deadlines for the application process, and required participant forms. This information is then used to generate a Memorandum of Understanding between EPIC and the MEP regions. Throughout the application process EPIC is in constant communication with MEP directors to assess the progress of their recruitment of students and completion of the application process. Due to the nature of frequent relocation of the MEP population it is difficult for the MEP coordinators to meet established application deadlines. Therefore, it is important to be in constant communication and allow some flexibility on the deadlines.

2. $\quad$ Awareness \& education about MEP

We put together an information sheet explaining MEP and EPIC's collaboration. It included background info on MEP and migrant students and was sent out to all EPIC lab instructors. This document can be found in Appendix II.

3. Diversity and Inclusion Training for counselors and lab instructors

We organized trainings for camp counselors and lab instructors on engaging students in engineering activities, with a focus on diversity and inclusion. We addressed stereotypes of engineering and how they can shape student's ideas of who becomes an engineer. We discussed the MEP/EPIC collaboration and provided guidelines for being a supportive mentor and instructor to each student. We emphasized the importance of using inclusive examples (i.e. Not all students have been to Disneyland or have smartphones), allowing students to use their native language when working in groups, and fostering a growth mindset by encouraging students to be curious and make mistakes.

4. Recruiting diversity of camp counselors

The EPIC director sought to recruit staff and camp counselors from a variety of backgrounds. We were able to hire 6 (out of 36) bilingual camp counselors and staff members. We reached out to multiple student organizations including Society of Professional Hispanic Engineers (SHPE), Society of Women Engineers (SWE), Women in Engineering Program (WEP), National Society of Black Engineers (NSBE), and Rising Immigrant Scholars through Education (RISE). 


\section{Translation services for camp materials}

We offered lab instructors Spanish translation services for their materials (i.e. worksheets, powerpoints, etc.). Since many MEP students are English learners, we thought that translating some materials or challenging words in presentations would support their success and comfort in the labs. There were no instructors who reached out for translating help beyond the 2 instructors from the previous year. This may have been due to lack of time, or we may need to emphasize the need more. We did translate the pre and post camp surveys and the IRB materials.

\section{Preliminary survey data analysis and staff reflection}

We created a pre/post survey to help us capture students' growth throughout their week at EPIC and evaluate the camp's effectiveness. Students and parents were told about the survey and asked to sign an IRB form, which was provided in English and Spanish. 137 out of 182 (75\%) students completed the post-survey properly and signed the IRB form--- 45 MEP students and 92 nonMEP students. Only 96 (52\%) completed the pre-survey and signed the IRB, so we did not include the survey data in this preliminary analysis. Below, we explore some of the post-survey data and share some reflections and observations some EPIC staff and the research team.

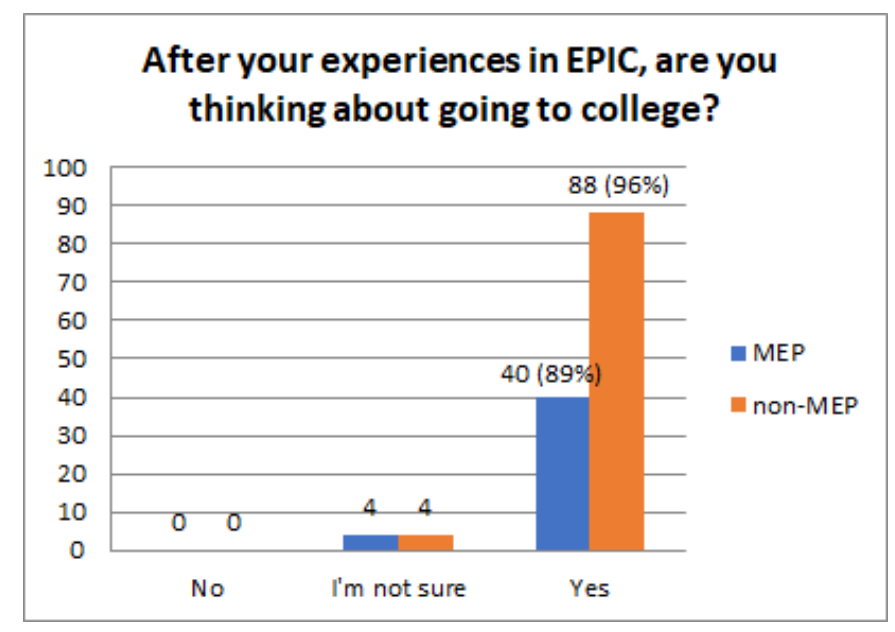

Figure 2: Graph of MEP and non-MEP students' response to post-survey question, "After your experiences in EPIC, are you thinking about going to college"

One of EPIC's primary goals is to encourage students to pursue higher education and expose them to resources that can support them. In Figure 2, we see that a majority of students left EPIC with motivation to consider going to college. Throughout their week with EPIC, students had the opportunity to be on a college campus, to get to know their counselors who are current college students, and to hear presentations on financial aid, admissions, and campus life. 


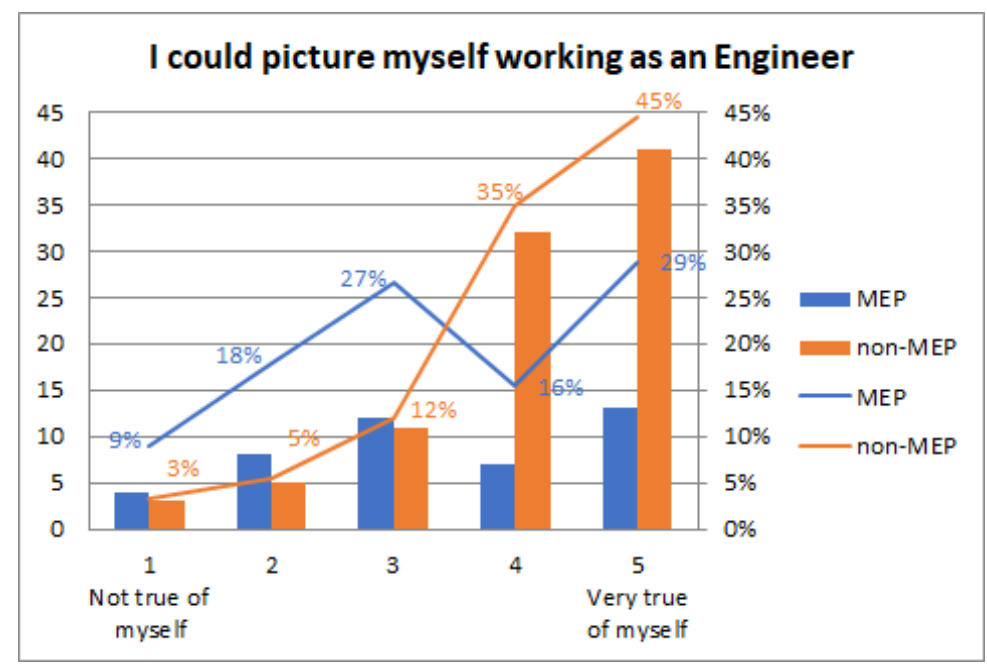

Figure 3: Graph of MEP and non-MEP students' response to post-survey Likert-scale question, "I could picture myself working as an Engineer"

In Figure 3, we see more of a discrepancy between MEP and non-MEP students regarding whether or not they can picture themselves working as engineers. We realize that students may still be uninterested in engineering after EPIC, and that is acceptable. We want students to be exposed and to have the option to choose an engineering field, but it's completely reasonable for students to be interested in something else. Still, it is important for us to be aware of any discrepancies between groups of students in case that it has something to do with how we are presenting engineering. Seeing role models that you can relate to is key to being able to see oneself as an engineer, and this is an area that EPIC can improve upon. Hiring diverse staff and lab instructors and providing more mentorship training may help MEP students, as well as other underrepresented minority students, envision themselves as engineers. While we tried to recruit a diverse staff, this was a challenge considering the demographics of our predominantly white and middle-upper class university community.

\section{Engagement \& Homesickness}

Throughout the week, there were a few MEP students who showed disinterest in the labs and other camp activities. This was revealed through staff observation and conversations between individual staff and students. For some of the students, they may have been placed in the camp versus selecting it for themselves which could help explain why they were unhappy about being there. For most of the MEP students, it was their first experience at an overnight camp which may have led to homesickness.

One of the lead staff members went above and beyond to connect with many of the MEP students. She was particularly passionate about working with this population because she related to their experiences and had worked with MEP children before. She worked closely with MEP students who expressed homesickness or disinterest during EPIC. She shared some observations:

"When these students were treated with a personal care and explained what the purpose of EPIC was, they change their behaviors. For example, one of the MEP students stopped eating and refused to talk; however, after sitting with him and asking him about his family, his likes, and telling him that he had been personally recommended by somebody 
that thought he could be an engineer. This made him feel important and that he belongs, and even though he was extremely introverted, by the end of the week he was smiling, talking, and trying to participate in both educational and social events."

During the evenings, there were challenges with many students (MEP and non-MEP) around bedtime and dorm rules. Students were told to stay in their dorm rooms after $10 \mathrm{pm}$ until the morning, but many students were found walking in the hallways and going into their friends rooms past this curfew. This caused a lot of concern around safety and noise issues, so all the students had to be addressed multiple times about respecting curfew.

We realized there were many underlying issues that led to students breaking curfew. As middle school students, most of the students had never been away from home for an overnight camp and this caused homesickness and anxiety, especially students who were paired with roommates they didn't know. Most of the MEP students did not have cell phones, and so many of them wanted to borrow friends' phones to call home. This was what led many students to break curfew and socialize later into the evening.

\section{Educating MEP families}

Due to the MEP families' institutional knowledge and background, many parents have a hard time understanding the benefit of a program like EPIC. Some families may prefer that their children work during the summer or help out at home. Because of this, some parents are not very supportive of their children attending camps like EPIC, especially if their children complain or seem unhappy there. Below, one of our lead staff members shared her interaction with one of the MEP students and her parents.

"One the campers said she felt sick, and wanted to go home; however, after talking to her it seemed that she wanted to go just to play a new video game that had been given to the family. The parents had agreed to drive three hours to pick her up, but one of the camp counselors talked to the parents before they made the final decision. She explained what the purpose of EPIC was and the cost of the camp; the parents were shocked because they could not even imagine being able to pay for EPIC. They commented that they had no idea what she was learning, and they just thought of it as a recreational field trip. The father talked about him not been able to attend grade school and asked the counselor if she genuinely believes his daughter could benefit. After the counselor explained her journey, the dad asked the daughter to engage in the camp and to take advantage and learn. The camper was a little frustrated at first, but after talking to her and helping her understand why her dad was so interested in her learning, she then actively engaged in the camp."

When the families were engaged and understood how a program like EPIC could impact the educational possibilities for their children, parents became more supportive, which was one of the experiences observed during EPIC. 


\section{Camp logistic challenges}

In regards to camp logistics, we faced some challenges with the evolving roster of the MEP students leading up to the camp. Since MEP is serving families who move frequently, the program had trouble solidifying the attendee list until right before the camp begins. This required us to be flexible since all other students had to apply and register for the camp a couple months prior to the start date. Even when we had a final count of MEP students, there were a few students who didn't show up either due to conflicting obligations or missing the MEP-sponsored transportation. It was hard reaching out to MEP families due to language barriers and the fact that the MEP directors were the primary point contact of communication with these families.

It was also difficult to get an exact count of MEP students participating in EPIC as we were planning the camp. This also made it challenging to fully understand the needs of students ahead of time (i.e. Who and how many students might benefit from being with a bilingual counselor?). Because of our relationship with MEP, we were able to work through this logistic challenge; however we can improve on our communications with them, so we can ensure that we meet the needs of all MEP students when they arrive to EPIC.

\section{Lessons learned}

As EPIC continues to work with MEP, we've identified some best practices and areas for improvement. Below are some areas that we will continue working on and hope may be useful for others:

\section{Partnership is important}

Our relationship with the program directors of MEP was essential to EPIC and MEP's partnership. As challenges arose during the camp, we were able were able to strategize together to support the MEP students through homesickness and other issues. The MEP directors had the trust of the students' parents, and so they handled communication with the parents prior to the camp and throughout it. As we continue working with these MEP directors, we will work to improve how we prepare students and set expectations for EPIC.

\section{2. $\quad$ Hire staff that can support and relate to students}

It is essential for EPIC to have camp counselors and staff who are passionate about diversity in education and who can be role models to our students. All students benefit from having roles models that look like them and can relate to their background, especially those who are underrepresented in engineering. While we were able to hire a relatively diverse staff this past summer, this is an area we need to continue working on. In particular, EPIC needs more counselors who are Spanish-speaking, first-generation college students, and people of color. It may also be helpful to have one of the MEP co-directors or staff members present throughout the week since the MEP students would already know and trust them. We will continue to strengthen our diversity and inclusion training, so our staff feels prepared to mentor students and support them if they feel homesick or a lack of belonging.

\section{Connect with students before they come to our campus}

We faced some challenges engaging students and maintaining community expectations (i.e. participation, curfew, phone usage). Connecting with students before the start of EPIC would help build excitement about EPIC and communicate expectations. The MEP directors were the 
primary points of contact for the students and parents prior to their arrival on our campus. It will be important for the MEP directors to continue these efforts, and, in addition, EPIC staff should also connect with MEP students and families. We would like to provide an orientation for MEP students and their parents, so they know what to expect and have a chance to answer questions and clarify any concerns. We might also consider inviting MEP students on campus during the school year to familiarize themselves with the environment.

\section{4. $\quad$ Foster supportive environment for homesickness}

Students must feel comfortable and cared for during their time at EPIC. Attending a week-long engineering camp at a university can be intimidating or unappealing to middle students for many reasons. As we mentioned, many students expressed homesickness which led to a variety of engagement and behavior issues. It is very important that we better prepare our counselors and staff to support students with homesickness. We also need to provide resources (phones and time), so students can call home regularly. By supporting students through homesickness and anxiety, they will be able to get much more out of their EPIC camp experience.

\section{Conclusion}

EPIC has made great strides in attracting and supporting a diverse group of students. There is still quite a bit of room for us to grow as we reflect on the past summer and listen to feedback from our students and staff. Our partnership with the Migrant Education Program has been a learning experience as we strive to better support their students and encourage them to pursue higher education and engineering disciplines.

We hope that this reflective paper is helpful to other summer camps and outreach programs that aim to broaden participation in engineering. We look forward to learning more from the engineering education community.

\section{References}

1. Chen, K.C., Schlemer, L.T., Scott, H.S. \& Fredeen, T. (2011), Evolving a Summer Engineering Camp through Assessment. ASEE Annual Conference Proceedings 2011

2. Chen, K.C., \& Belter, D., \& Fredeen, T., \& Smith, H., \& Magnusson, S. (2009), Inspiring A Diverse Population Of High School Students To Choose Engineering As A Career Path. ASEE Annual Conference Proceedings 2009 


\section{Appendix I}

EPIC Session 1 July 8-13, 2018

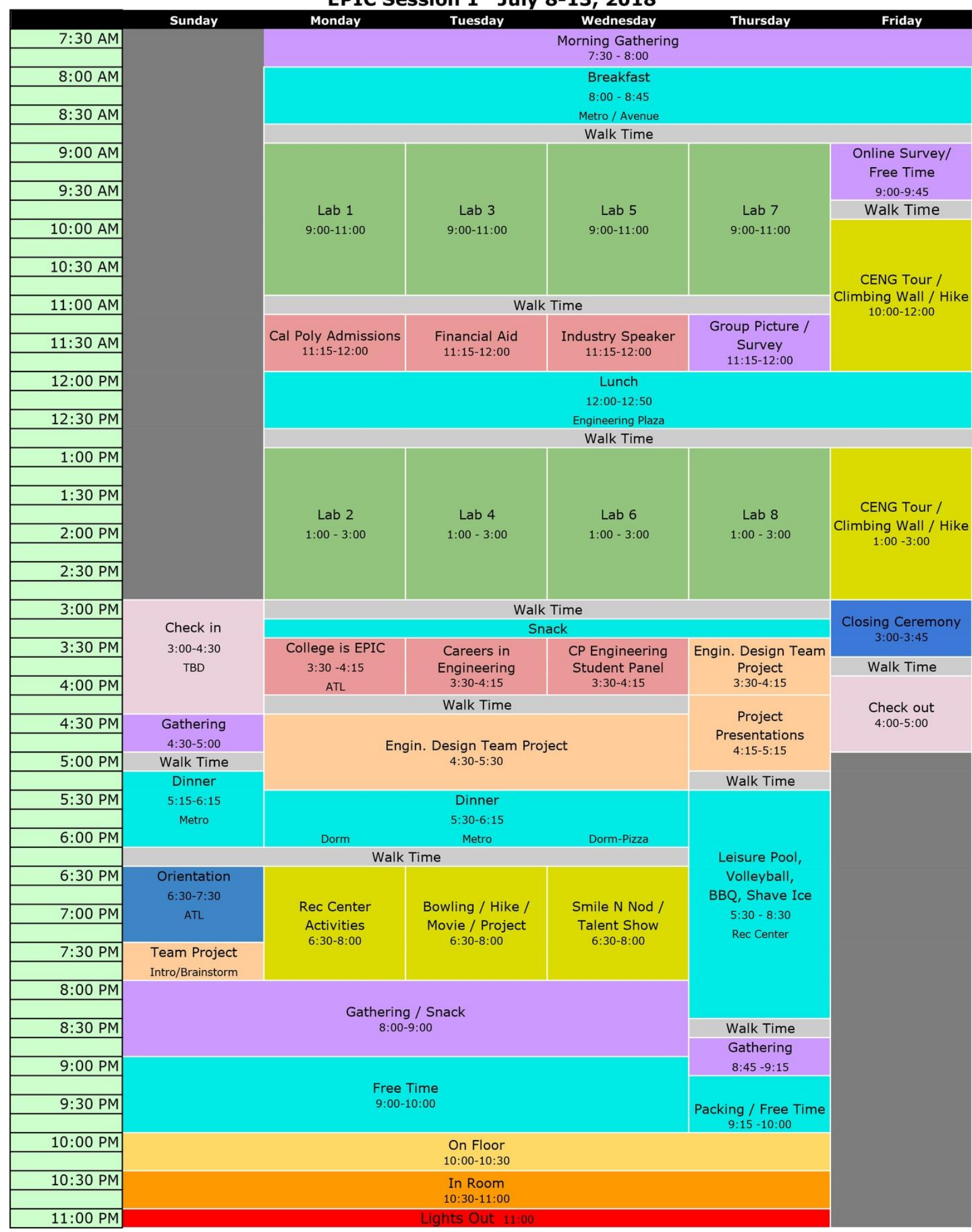




\section{Appendix II}

\section{Migrant Education Program \& EPIC 2017}

The founding goal of the EPIC (Engineering Possibilities In College) summer camp (established in 2007) has been to provide hands-on opportunities to experience, learn about, and inspire engineering for younger students, especially those from underrepresented groups. EPIC encourages students to consider the possibility of studying engineering in college.

\section{What is the relationship between the Migrant Education Program and EPIC?}

This year, EPIC is collaborating with the Migrant Education Program Regional Offices to expand access to hands-on learning experiences for migrant students. There will be a total of 85 Migrant Students participating in EPIC this summer. 66 Migrant Students will participate in Session 1: Grades 7-9, and the other students will be attending Sessions 2-4 for high school students.

\section{What is the Migrant Education Program?}

The Migrant Education Program is a federally funded program that works with migrant students to help reduce the educational disruptions and other problems that result from repeated moves.

See more information at:

http://www2.ed.gov/programs/mep/index.html

http://www.cde.ca.gov/sp/me/mt/programs.asp

\section{Who are Migrant Students?}

Migrant Students are children of workers who work in the agricultural, dairy, lumber, or fishing industries and whose family has moved at least once in the past three years due to employment.

\section{What are some obstacles that Migrant Students face?}

- Due to agricultural seasons, students may be required to move in the middle of the school year and may attend multiple schools each year.

- Due to constant moving, transferring credits between different school districts can be difficult as each district has its own requirements for graduation. $50 \%$ of migrant students end up dropping out of high school.

- A majority of Migrant Students are considered low income and approximately $50 \%$ of them are considered homeless.

- Migrant students may find it difficult to establish long lasting relationships with other students are their teachers

- For most of the students, their families are not fluent in English which creates a communication gap between the school and parents 


\section{What are some strength skills that Migrant Students bring?}

Even with all these obstacles that Migrant Students go through, Migrant Students also have a lot of strength skills including:

- Resilience

- Commitment to Hard Work

- Ability to Speak Multiple Languages

○ Many migrant students are Spanish speakers. Note, however, that other Migrant Students are Mixteca speakers and may or may not also speak Spanish.

\section{How can I support Migrant Students during EPIC as a Lab Instructor?}

To best support Migrant Students (and all students in EPIC), it is very important that Lab Instructors create an inclusive environment by encouraging respect for and celebration of differences, create a positive learning environment, and allow students to demonstrate their individual knowledge.

Here are eight best practices for working with diverse groups of students, including migrant students:

1. Ensure good visuals on presentations that can support students who are Englishlanguage learners. Example: Show lab set-ups and activities with pictures in addition to explaining through words.

2. Allow and encourage students to work in multiple languages during the lab. Most of these migrant students know more than one language and studies show that switching between languages is a sign of great critical thinking skills.

3. Are your students doing group work? Assign groups rather than allowing students to choose their own groups. Migrant students should have the opportunity to work with Non-Migrant Students in group work.

4. Want to have a group discussion? Provide opportunities for students to talk with each other about your question (a "pair-share") beforehand. This provides an opportunity for students to prepare their answers in English.

5. Want to have students present? Give all students the opportunity to prepare their presentations and utilize presentation groups of 2 or 3 students rather than a single student.

6. Provide individual support to each student. Making personal connections can encourage shy students and boost their confidence.

7. Do not assume that students in your session will have had access to educational experiences such as utilizing computers as a tool. Provide support for students with a range of previous educational experiences.

8. If a student reveals his/her background to you or a group, respect that student's decision to disclose sensitive information. 